\title{
Severe Seoul hantavirus infection in a pregnant woman, France, October 2012
}

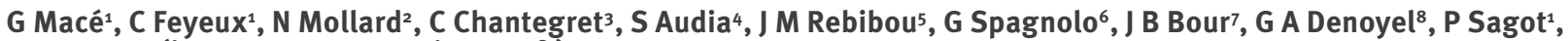
J M Reynes (jean-marc.reynes@inserm.fr) ${ }^{2}$

1. Department of Obstetrics and Gynecology, Centre Hospitalier Universitaire (CHU) Bocage, Burgundy University, Dijon, France

2. Centre National de Référence des Hantavirus, Unité de Biologie des Infections Virales Emergentes, Institut Pasteur, Lyon, France

3. Neonatal Intensive Care Unit, CHU Bocage, Burgundy University, Dijon, France

4. Department of internal medicine, CHU Bocage, Burgundy University, Dijon, France

5. Intensive Care Unit of Nephrology, CHU Bocage, Burgundy University, Dijon, France

6. Department of Obstetrics and Gynecology, Centre Hospitalier, Mâcon, France

7. Department of Virology, CHU Bocage, Burgundy University, Dijon, France

8. Department of Virology, Biomnis, Lyon, France

Citation style for this article:

Macé G, Feyeux C, Mollard N, Chantegret C, Audia S, Rebibou JM, Spagnolo G, Bour JB, Denoyel GA, Sagot P, Reynes JM. Severe Seoul hantavirus infection in a pregnant woman, France, October 2012. Euro Surveill. 2013;18(17): pii=20464. Available online: http://www.eurosurveillance.org/ViewArticle. in a pregnant woman,

Article submitted on 17 April 2013 / published on 25 April 2013

We report the first detection of Seoul virus (SEOV) in humans in Europe, causing severe disease in a pregnant woman in France in October 2012. The patient's laboratory test results mimicked that of pregnancyinduced liver pathologies such as acute fatty liver of pregnancy (AFLP) with severe renal failure. This led to an emergency delivery (at 27 weeks' gestation). On the basis of gene $S$ (small) sequence analysis, the Seoul hantavirus strain detected was found to belong to the main SEOV phylogroup.

\section{Case report}

A primigravida woman in her mid-20s presented at 26 weeks of gestation in October 2012 with blurred vision, chills, headache, back pain and cough that had lasted two days. Her previous medical history was unremarkable. Physical examination revealed a high body temperature $\left(39.1^{\circ} \mathrm{C}\right)$. The fetal heart rate was normal and there was no uterine contraction. Antibiotics (ampicillin and gentamicin) were introduced systematically. Two days later (four days after symptom onset, day 4), she was transferred to the regional reference hospital because of abnormalities in test results from blood and urine sampled at day 3 (Table).

On admission to the department of obstetrics and gynaecology, she had no fever, hypertension or haemorraghic symptoms. The admission laboratory results (day 4 showed an elevated C-reactive protein without lymphocytosis, elevated levels of liver enzymes, thrombocytopenia and mild coagulopathy (Table). Serological investigations were requested, to test for leptospirosis, toxoplasmosis, viral hepatitis, and herpes simplex viruses, cytomegalovirus, EpsteinBarr virus and hantavirus infection. Abdominal sonography showed no hepatobiliary pathology, but the presence of only one kidney. Obstetric examination and ultrasound were normal, with normal fetal growth. The patient was closely monitored and antenatal prophylactic application of steroids (betamethasone, $12 \mathrm{mg}$ per day for two days) for fetal pulmonary maturation was given. On day 7 , the patient developed acute renal failure (creatininemia at $260 \mu \mathrm{mol} / \mathrm{L}$ ) (norm: 53-115 $\mu \mathrm{mol} / \mathrm{L})$ (Table) with microscopic haemoglobinuria, proteinuria and anaemia. An emergency Caesarean section was performed on day 7 (at 27 weeks and two days' gestation) because of suspected acute fatty liver of pregnancy (AFLP) and to preserve maternal renal function in a patient with only one kidney. The preterm baby weighed 1,095 $\mathrm{g}$ when born and was intubated for respiratory distress syndrome.

After the birth, the mother was immediately transferred to a nephrology intensive care unit. Liver enzymes, blood count and coagulation normalised first, then renal function increased and was within the normal ranges within three weeks (Table), without the need for dialysis.

The newborn remained in a stable condition in the intensive care unit. Blood cultures and histological examination of placenta were normal. At five months of age, hypertonia and spasticity in the muscle of the lower extremities remained.

\section{Etiological investigation}

The tests were negative for leptospirosis, toxoplasmosis, viral hepatitis, and herpes simplex viruses, cytomegalovirus, Epstein-Barr virus infection.

Tests for the detection of IgM and IgG against hantaviruses using Hantavirus IgG DxSelect and Hantavirus IgM DxSelect (Focus Diagnostics) were positive on a serum sample collected on day 7. As usual in France 
Blood and urine biochemical findings during hospitalisation of the Seoul hantavirus-infected patient, France, October 2012

\begin{tabular}{|c|c|c|c|c|c|c|c|c|c|c|c|c|}
\hline \multirow{2}{*}{ Specimen } & \multirow{2}{*}{ Parameters } & \multirow{2}{*}{ Unit } & \multirow{2}{*}{ Norm } & \multicolumn{9}{|c|}{ Day of sampling ${ }^{a}$} \\
\hline & & & & Day 2 & Day 3 & Day 4 & Day 5 & Day 7 & Day 8 & Day 10 & Day 15 & Day 36 \\
\hline \multirow{12}{*}{ Blood } & White blood cells & $10^{9} / \mathrm{L}$ & $4-10$ & 6.5 & 6.2 & 7.4 & 9.4 & 18 & 12.1 & 12 & 6.4 & 6.9 \\
\hline & \begin{tabular}{|l|} 
Platelets \\
\end{tabular} & $10^{9} / \mathrm{L}$ & $150-450$ & 133 & 95 & 44 & 70 & 125 & 93 & 207 & 371 & 392 \\
\hline & Haemoglobin & $\mathrm{g} / \mathrm{dL}$ & $11.5-16.0$ & 11.2 & 11.6 & 12.9 & 11.5 & 9.3 & 8.2 & 8.5 & 8.3 & 10.7 \\
\hline & C-reactive protein & $\mathrm{mg} / \mathrm{L}$ & $\ll 3.2$ & 17 & 59 & 133 & 114 & 49.9 & ND & 99.8 & 15.1 & $<2.9$ \\
\hline & Lactate dehydrogenase & $\mathrm{IU} / \mathrm{L}$ & $120-228$ & ND & ND & 965 & 913 & 407 & 329 & ND & 223 & ND \\
\hline & $\begin{array}{l}\text { Aspartate } \\
\text { aminotransferase }\end{array}$ & $\mathrm{IU} / \mathrm{L}$ & $15-37$ & ND & ND & 785 & 792 & 259 & 169 & 98 & 17 & ND \\
\hline & Alanine transaminase & $\mathrm{IU} / \mathrm{L}$ & $9-52$ & ND & ND & 333 & 347 & 178 & 128 & 94 & 31 & ND \\
\hline & \begin{tabular}{|l|} 
Gamma- \\
glutamyltransferase
\end{tabular} & $\mathrm{IU} / \mathrm{L}$ & $5-55$ & ND & ND & 133 & 132 & 293 & ND & 221 & 131 & ND \\
\hline & Prothrombin ratio & $\%$ & $70-100$ & ND & ND & 74 & 89 & 94 & 94 & 97 & 100 & ND \\
\hline & Partial prothrombin time & s patient / s control & $0.8-1.2$ & ND & ND & 2.1 & 1.7 & 0.95 & 0.98 & 1.05 & 1.06 & ND \\
\hline & \multirow{2}{*}{ Creatinine } & $\mu \mathrm{mol} / \mathrm{L}$ & $53-115$ & 42 & ND & 61 & 67 & 260 & 328 & 648 & 295 & 63 \\
\hline & & $\mathrm{mg} / \mathrm{L}$ & $5-12$ & ND & 1.17 & ND & ND & ND & ND & ND & ND & ND \\
\hline Urine & Proteinuria & $\mathrm{g} / 24 \mathrm{~h}$ & $<0.3$ & ND & ND & ND & ND & 3.35 & ND & 0.65 & ND & ND \\
\hline
\end{tabular}

IU: international unit; ND: not done.

a The sampling day refers to the number of days after symptom onset.

for surveillance purposes, the positive sample was then transferred to the National Reference Centre for Hantavirus, where these positive results were confirmed by an enzyme-linked immunosorbent assay (ELISA) developed in-house using Hantaan virus (HTNV) and Puumala virus (PUUV) antigens [1].

The information sheet received with the sample reported that the place of residence of the patient was not in the north-east of France, where PUUV infection in humans are usually detected [2] and that the patient had not visited this endemic region in the previous month. Consequently, the emergence of PUUV at the patient's place of residence or the presence of another hantavirus was suspected. Therefore, the serum sample collected on day 4 , which had been stored at -20 ${ }^{\circ} \mathrm{C}$, was sent to the National Reference Centre for Hantavirus and tested for the presence of hantavirus RNA. The assay was positive using pan-hantavirus nested reverse transcription polymerase chain reaction (RT-PCR) targeting a part of L segment, Murinae-borne hantavirus nested RT-PCR targeting a part of S segment, and HTNV as positive control [3,4]. Amplicons were sequenced and a BLAST search indicated that the sequences were very close to those of Seoul (SEOV) strains (data not shown).

Then the complete $\mathrm{S}$ coding domain sequence was recovered via three nested RT-PCRs with in-housedesigned primers (protocol available on request from the authors), producing three overlapping amplicons
(GenBank accession number KC902522). The amino acid sequence was identical to those of SEOV strains found in the United Kingdom, Vietnam, South Korea and China (GenBank accession numbers JX879769, AB618112, NC_005236 and GU592947, respectively). It was also identical to the partial $S$ coding domain sequence obtained from the SEOV strain detected in rodents in France [5]. Using MEGA version 5.1 [6], phylogenetic analysis based on $\mathrm{S}$ coding domain sequence confirmed that the strain - named REPLONGES/Hu/ FRA/2012/12-0882 - belonged to SEOV species, especially to the main phylogroup, which includes strains from Asia and the rest of the world [7] (Figure).

\section{Background}

Five zoonotic hantaviruses have been described in Europe: PUUV, Dobrava-Belgrade (DOBV), Tula (TULV), Saaremaa (SAAV), and SEOV. These rodent-borne hantaviruses cause mild to severe haemorrhagic fever with renal syndrome. PUUV and DOBV are responsible for most human cases detected in Europe [8-10]. TULV and SAAV viruses have been only found in rodent samples; rare human cases have been serologically confirmed [8-10]. SEOV, a ubiquitous hantavirus, has been rarely detected in Europe in the brown rat, Rattus norvegicus, one of its rodent hosts. Few human cases have been suspected and serologically confirmed $[8,11,12]$.

\section{Epidemiological investigation}

The investigation was limited to an interview of the patient. The patient lived in a village near the Saône 


\section{FIGURE}

Phylogenetic tree based on the entire gene S (small) nucleotide coding sequence from the patient with Seoul virus infection, France, October 2012, and representative strains of Seoul virus and other hantavirus species

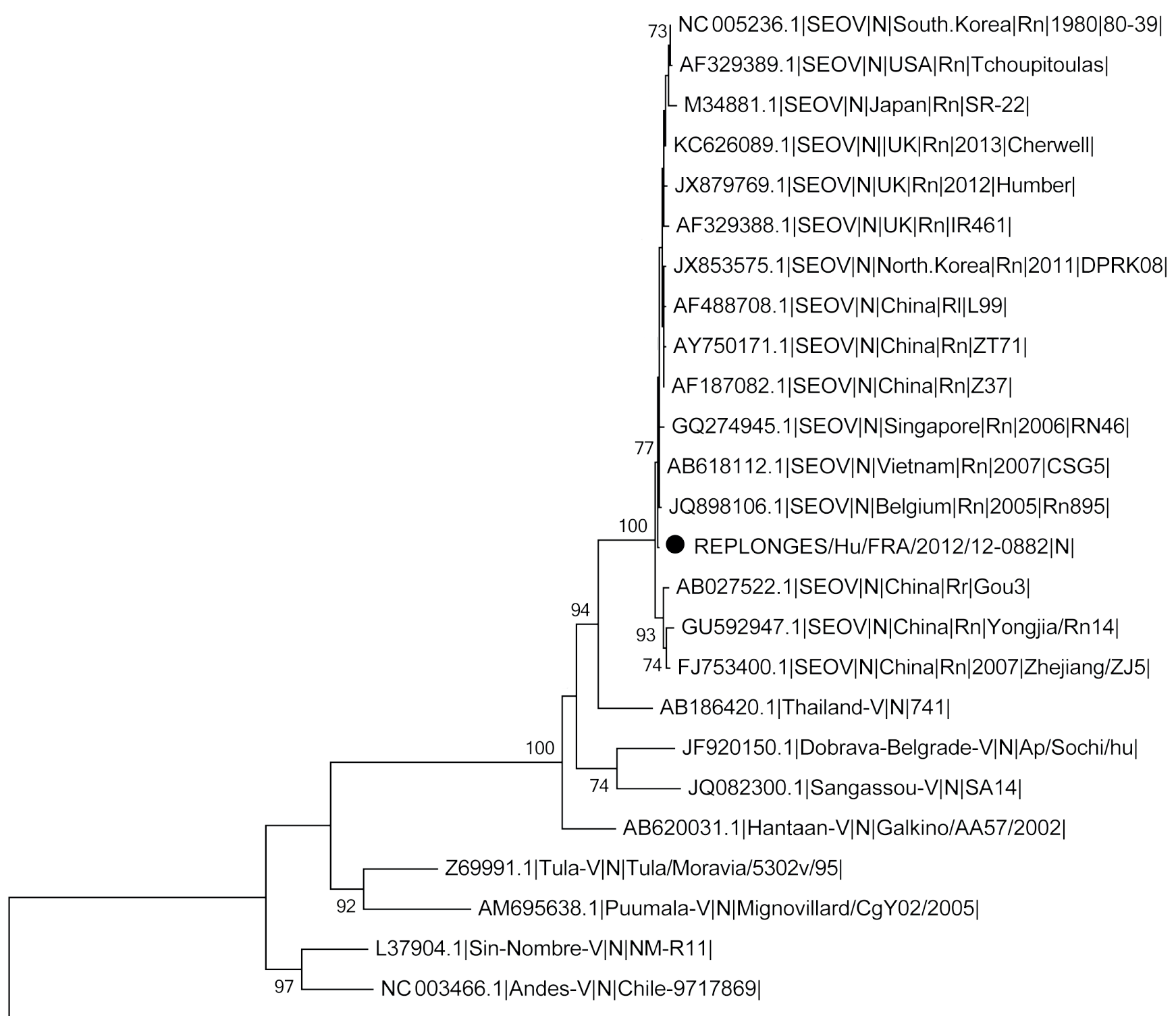

JF784176.1|Thottapalayam-V|N|Longwan/Sm512|

0,2

The patient's strain, REPLONGES/Hu/FRA/2012/12-0882, is indicated by

Bootstrap percentages $\geq 70 \%$ (from 1,000 resamplings) are indicated at each node. The scale bar indicates nucleotide substitution per site.

Using MEGA version 5.1, sequences were aligned by ClustalW and the maximum likelihood method was used: according to the best fit substitution model proposed, analysis was performed applying the generalised time reversible model using a Gamma distribution (+ $\mathrm{G})$ with five rate categories. 
River in the Ain department (about $350 \mathrm{~km}$ south-east of Paris). She did not work during the six weeks before symptom onset and did not report apparent exposure to rodents at home or in her mother's house, which she visited several times during this period. The only indirect contact with rodents during that period was thought to have occurred when picking mushrooms in a forest close to a rural village in the Rhone department, about $25 \mathrm{~km}$ south-west from her home. Many unidentified rodents were observed by the patient in the forest, running at ground level. Investigation of rodents is the area is not yet planned.

\section{Discussion}

To the best of our knowledge, that is the first report of SEOV infection in a pregnant woman, although we suppose such cases of infection may have been suspected or detected in Asia $[13,14]$. The clinical and biological picture of our case was confusing because distinguishing between this SEOV infection and certain liver pathologies of pregnancy, especially severe preeclampsia with haemolysis, elevated liver enzymes and low platelet count (HELLP) syndrome and AFLP was problematic. Such syndromes have been suspected in pregnant women infected with hantaviruses [13-15]. In women with elevated levels of liver enzymes, thrombocytopenia and renal failure during pregnancy without hypertension, especially when laboratory test results are atypical and the symptoms begin with fever, practitioners should consider possible hantavirus infection instead of pregnancy-induced pathologies, which could potentially avoid emergency delivery and thus newborn prematurity.

As in the rest of Europe, data regarding SEOV in France are very scarce. The virus was detected in 2003 in reared brown rats in Lyon (about $60 \mathrm{~km}$ south of the patient's home), one human case was serologically confirmed (by neutralisation assay) and others suspected $[2,5,8]$. Routine serological tests do not allow discrimination between SEOV and PUUV infections and the demand for hantavirus testing in France, especially for mild cases, is limited because these tests are not free of charge. Therefore, the occurrence of SEOV infections in humans is probably underestimated. Large studies focusing on the epidemiology of SEOV infection should be conducted in France as well in the rest of Europe, as serologically confirmed cases have been recently described in the United Kingdom [11-12].

\section{Acknowledgements}

The Centre National de Référence des Hantavirus receives financial support from the Institut de Veille Sanitaire (InVS) (http://www.invs.fr/).

Authors' contributions

Guillaume Macé, Cécile Feyeux, Corinne Chantegret, Sylvain Audia, Jean-Michel Rebibou, Gilles Spagnolo, Jean-Baptiste Bour and Paul Sagot took care of the patient and her child. Gérard-Antoine Denoyel performed hantavirus serological analysis. Nadège Mollard and Jean-Marc Reynes performed hantavirus serological analysis, SEOV detection and molecular analysis of the SEOV strain. Guillaume Macé and JeanMarc Reynes wrote the manuscript. All co-authors reviewed the manuscript.

\section{Conflict of interest}

None declared.

\section{References}

1. Rossi CA, Ksiazek TG. Enzyme-linked immunosorbent assay (ELISA). In: Lee HW, Calisher CH, Schmaljohn C, editors. Manual of hemorrhagic fever with renal syndrome and hantavirus pulmonary syndrome. Seoul: Asan Institute for Life Sciences; 1999. p. 87-89.

2. Le Guenno B. [Hantaviruses]. Med Mal Infect. 1997;27(6-7):70310. French.

3. Papa A, Johnson AM, Stockton PC, Bowen MD, Spiropoulou CF, Alexiou-Daniel S, et al. Retrospective serological and genetic study of the distribution of hantaviruses in Greece. J Med Virol. 1998;55(4):321-7.

4. Klempa B, Fichet-Calvet E, Lecompte E, Auste B, Aniskin V, Meisel $\mathrm{H}$, et al. Hantavirus in African wood mouse, Guinea. Emerg Infect Dis. 2006;12(5):838-40.

5. Heyman P, Plyusnina A, Berny P, Cochez C, Artois M, Zizi M, et al. Seoul hantavirus in Europe: first demonstration of the virus genome in wild Rattus norvegicus captured in France. Eur I Clin Microbiol Infect Dis. 2004;23(9):711-7.

6. Tamura K, Peterson D, Peterson N, Stecher G, Nei M, Kumar S. MEGA5: molecular evolutionary genetics analysis using maximum likelihood, evolutionary distance, and maximum parsimony methods. Mol Biol Evol. 2011;28(10):2731-9.

7. Lin XD, Guo WP, Wang W, Zou Y, Hao ZY, Zhou DJ, et al. Migration of Norway rats resulted in the worldwide distribution of Seoul hantavirus today. J Virol. 2012;86(2):972-81.

8. Olsson GE, Leirs $H$, Henttonen $H$. Hantaviruses and their hosts in Europe: reservoirs here and there, but not everywhere? Vector Borne Zoonotic Dis. 2010;10(6):549-61.

9. Vaheri A, Henttonen H, Voutilainen L, Mustonen J, Sironen T, Vapalahti O. Hantavirus infections in Europe and their impact on public health. Rev Med Virol. 2013;23(1):35-49.

10. Klempa B, Avsic-Zupanc T, Clement J, Dzagurova TK, Henttonen $\mathrm{H}$, Heyman $\mathrm{P}$, et al. Complex evolution and epidemiology of Dobrava-Belgrade hantavirus: definition of genotypes and their characteristics. Arch Virol. 2013;158(3):521-9.

11. Jameson LJ, Taori SK, Atkinson B, Levick P, Featherstone CA, van der Burgt $G$, et al. Pet rats as a source of hantavirus in England and Wales, 2013. Euro Surveill. 2013;18(9):pii=20415. Available from: http://www.eurosurveillance.org/ViewArticle. aspx?Articleld $=20415$

12. Jameson LJ, Logue CH, Atkinson B, Baker N, Galbraith SE, Carroll MW, et al. The continued emergence of hantaviruses: isolation of a Seoul virus implicated in human disease, United Kingdom, October 2012. Euro Surveill. 2013;18(1): pii=20344. Available from: http://www.eurosurveillance.org/ViewArticle. aspx?Articleld $=20344$

13. Howard MJ, Doyle TJ, Koster FT, Zaki SR, Khan AS, Petersen EA, et al. Hantavirus pulmonary syndrome in pregnancy. Clin Infect Dis. 1999;29(6):1538-44.

14. Hofmann J, Führer A, Bolz M, Waldschläger-Terpe J, Meier $M$, Lüdders D, et al. Hantavirus infections by Puumala or Dobrava-Belgrade virus in pregnant women. J Clin Virol. 2012;55(3):266-9.

15. Schneider F, Vidal L, Auvray C, Khider Y, Graesslin O. [The first French hemorrhagic fever with renal syndrome in pregnant woman]. J Gynecol Obstet Biol Reprod (Paris). 2009;38(5):4402. French. 